\title{
XLVIII. Account of the meteor seen on the evening of Sunday, November 13th. 1803; with some observations on the best means of ascertaining the altitude, bearing, magnitude, distance, and velocity of such phenomena
}

\section{Mr. T. Firminger}

To cite this article: Mr. T. Firminger (1803) XLVIII. Account of the meteor seen on the evening of Sunday, November 13th. 1803; with some observations on the best means of ascertaining the altitude, bearing, magnitude, distance, and velocity of such phenomena, Philosophical Magazine Series 1, 17:67, 279-284, DOI: 10.1080/14786440308676414

To link to this article: http://dx.doi.org/10.1080/14786440308676414

曲 Published online: 18 May 2009.

Submit your article to this journal 주

Џll Article views: 2 
XLVIII. Account of the Meter seen on the Evering of Sunday, November 13th. 1803; with some Olservations on the best Means of ascertaining the Altitude, Bearing, Magnitude, Distance, and Velocity of such Phenomena. By Mr. T. Firminger.

I

was at first advertised of the appearance of this meteor by a very strong light which rendered all the surrounding objects visible: it was, indeed, so very bright that I could have read a newspaper by it without the least difficulty. I no sooner saw this light 1 ban I was apprehensive of the cause which produced it, and upon looking up saw the meteor to the south of the zenith, and about twenty-five degrees in azimuth to the east of the meridian; it was then moving with a great velocity towards the west in a mather north-westcrly direction; its course, however, was very nearly in a line perpendicular to the meridian.

At its first appearance it seemed quite round, and well defined, except the part opposite to the direction in which it was moving, which seened to project a little, and to terminate in a tail that extended to a small distance from it (see uppermost figure, Plate VI.) On each side of this ta!l there were two or three smaller balls, tinged at their extremities with yellow and orange colours, and one or two with purple. The whole body continued to move together without any sensible difference in either its colour or shape till within about a second or a second and a half before its disappearance, when it suddenly altered its figure to something like the shape of an egg, (see the lower figure, in which $A B$ represents the direction of its motion.) Aithis moment its light became so strong that it was not without much difficulty I was able to keep looking at it. I should think its light was full two-thirds as intense as that of the sun when upon the meridian. It seemed at this time as if the meteor had before becn covered with one external coat, which now burst or separated in the middle the whole length of its longest diameter, and exposed a surface with a brightness far surpassing its former lustre. I mav, however, have overrated its light, hy supposing it equal to twothirds of that of the sum when upon the moridian, for it is to be observed that the pupil of my eye must have been before much dilated from the darkness of the night, to which it had been exposed at least a quarter of an hour; but the comparison relates th the effect it produced upon my 
eyes at that moment, when compared to what the direct rays of the sun would produce in the middle of the day.

The diameter of the large ball at its first appearance, by comparing it with the moon, (which is the best object 1 know of for that purpose) I should think subtended an angle of at least twenty minutes of a degree; the smaller balls, which appeared all nearly of the same size, were about a fifth part of the diameter of the large one, and I should suppose subtended angles of about four or tive minutes of a degree. The alitude of the meteor was about 50 or 55 degrees, and continued nearly the same during the whole time of its appearance, which was about four seconds and a half or four and three quarters; it vanished instantaneously with an azimuth of about 75 degrees to the west af the meridian.

The azimuth and altitude were afterwards estimated by means of a needle and compass and a small Gunter's quadrant, which I tork to the place where I stood when I saw the meteor, and they are I believe preity correct, as the surrounding objects assisted me very much in making these estimates. I also measured with a sextant the apparent path which it described, and found it about 85 degrees. Its disappearance was at $8^{\mathrm{h}} 30^{\mathrm{m}} 39^{\mathrm{s}}$ mean time, which I had an opportunity of ascertaining by an excellent chronometer of Mr. Earnshaw's construction which I happened to have with me.

In two minutes after the appearance of this meteor I heard a noise which sounded like a distant clap of thunder, or like the rumbling of a coach heard at a quarter of a mile's distance going over a stone pavement; it was pretty loud at first, but got gradually fainter until it was no longer andible, and, what was very surprising, it seemed to follow the very same track the meteor before had appeared to move in : it lasted a minute and forty seconds.

The appearance of the meteor as it moved along had a very great resemblance to that of a skyrocket seen at the distance of about a mile. I have aiso since met with per.. sons who have seen meteors, and they have generally described their appearance as very much rescmbling that of a skyrocket, which may have induced some observers of these phenomena to think they heard a hissing noise something like what these rockets occasion; for the imagination is se forcibly impiessed by such comparisons, and the dnration of the appearance of meteors so very short, that it is not at all surprising wo should be misled in our ideas, and 
combine appearances with sensations which have no other existence than in the imagination.

The noise that followed after this meteor was particularly noticed by several people, who, although they saw nothing of the appearance, yet were alarmed by the singularity of the noise : some conjectured it to be occasioned by the oversetting of a coach, others by the rattling of a fire-engine, and others by a distant clap of thunder.

With respect to the height of this meteor, or its dimensions, nothing more can at present be inferred than what is derived by comparing the interval of time elapsed between seeing the meteor and hearing the noise which it occasioned in its passage through the upper regions of the atmosphere. By that interval of time, its distance from me when first observed would appear to have been about six and twenty miles; and its perpendicular height about three and twenty miles above the earth's surface.

This method of obtaining its distance, however, must be liable to great uncertainty, and can only be adopted as an approximation, where better means are not to be obtained; for although the velocity of sound is pretty well ascertained at distances near the earth's surface, yet its velocity at the height of twenty-three miles above the earth may be very different from what our calculations give it. The real distance, therefore, can only be obtained, with any degree of accuracy, by observations made at different places at a considerable distance from each other. It is much to be wished that people, who happen to be so situated as to have an opportunity of observing a meteor, would take ald possible pains in the first place to obtain its altitude as correctly as they can, which may oftentimes be done with great accuracy; for although the mind at the moment may be altogether engaged in admiring the beautiful and curious appearance of such a singular phenomenon, yet I believe it will be generally in our power to remember the precise place where we were when such a circumstance happened: for people in general stand still when any thing chances to strike them with surprise, and before they proceed to remove from that place take notice of the objects that sur= round them : and hence it very naturally follows, that when we give an account of the appearance of any phenomenon, we are always particular in our description of the spot from whence we saw it. If, therefore, at a considerable time after, we were to go to the place where we saw a meteor, the strong impression left on the imagination of its apparent situation would enable us to ascertain its altitude without 
being liable to a mistake of more than about ten degrees; and in a close situation, as in a street, or among houses, it will oftentimes happen that some object will intercept part of its course from the observer's sight, and then he may ascertain its altitude to a much greater degree of accuracy; I should think, in such a case, he will seldom be liable to an error of more than five degrees, and in general will be able to come nearer; but eren where the surrounding objects are not so favourably situated, they will, if they happen to lie in the direction in which the meteor is seen, be always found of great service in assisting the necessary estimates afterwards.

Those, therefore, who have had an opportunity of observing a meteor, should, as soon as possible, repair to the place where they stood when they saw it, and by means of a common or Gunter's quadrant, or any other instrument that will measure altitudes, endeavour to obtain its height as correctly as they can; and at the same time, with a needle and compass, take its bearing at that part of its course where its altitude was measured. If, however, the observer should not happen to be furnished with any instruments for mcasuring altitudes or bearings, yet if he has bcen so fortunate as to have compared it with any fixt object, or has seen its course intercepted by the top of a house, a church, or any other body, and can recollect the place where he stood at the time, its situation may be pretty correctly ascertained; for if he measures the distance from the place where he stood to the object, and then measures the height of the object behind which it disappeared, its altitude may be easily inferred; and by comparing the direction of such object with the north and south, or east and west, points, its bearing at that inne will be had sufficiently near to be of considerable service, as it is not necessary to be so correct in this respect as in obtaining its altitude, though the nearer we can come at both the better.

If the observer should happen to be in a fiekd, or any apen place where there are no ncighbouring objects to assist him in his ertimation, he will, however, be able to obtain its altitude and bearing, in the following manner : Let him go to the place where he stood when he saw the meter, and there having fixed up a rod or stick perpendicular on the ground, of a sufficient length, according to the height at which the meteor appeared, let hin recede from the stick until, by looking over the top of it, he see the top in a line with the place in which he before observed the meteor to appear: if he then weasures his distance from the stick, 
stick, and the height of his eye from the level with the bottom, and lastly the length of the stick, he will be able to obtain its altitude pretty correctly ; and also, by observing the direction the stick bears from him, will obtain at the same time its azimuth. For this purpose the stick should be chosen of such a length that he may be able to recede from it to the distance of six or eight feet at least. Many people, however, who may have an opportunity of seeing meteors and putting the above method in practice, for want of mathematical information, may not be able to make the necessary calculations ; but no loss will be sustained in this case, provide such gentlemen would be careful to take their measures as correctly as possible, and publish an account of them, with a sketch of the method they made use of, which would enable others to draw such conclusions as might be necessary for their purpose, or at least be of great use to them.

The altitude and bearing at the time are the most necessary to be known. The apparent diameter, time of duration, and extent of the track through which the phenomenon move may, hawever, be of great service when they can be obtained with any tolerable degree of accuracy. But here I must observe', that all estimations of altitudes without instruments or any means of measuring are too fallacious to be depended on, and can seldom or ever be admitted into computation. Let any one go out in the evening, and endeavour to estimate the altitude of a star, or any other object, and he will soon find himself liable to an error of twenty or thirty degrees, generally estimating the altitude too high. This I particularly instanced in the appearance of the meteor I have here described ; for, before I measured its altitude with a quadrant, I had estimated it fifteen or twenty degrees higher than it was. In ascertaining the apparent magnitude of meteors it has been, I believe, the most usual way to compare their appearance with that of the moon; and if the moon is visible at the time, it will afford a pretty good object for that purpose; but if the moon should not be visible, it must be liable to a considerable degree of uncertainty.

The apparent diameter of the meteor here mentioned I have supposed to subtend an angle of not less than twenty minutes of a degree, which, with the distance deduced from the interval between the appearance of the meteor and hearing the sound, gives its real diameter nearly 280 yards, or almost half a mile in circumference; and also, by comparing the extent of track through which it moved with the 
time of its duration, its velocity will appear to have been between scven and eight miles in a second:-a velocity which more than twenty times exceeds the greatest velocity of a cannon ball, and can only be compared to what we at present know of the amazing velocity of electricity.

In accounting for the nature and production of meteors, it is evident that nothing can help us in our inquiries so much as a knowledge of their dimensions, their distance, and the extent of space through which they move; and these are only to be obtained by good observations. Although their appearance and the manner in which they burst are very curions, and should as much as possible be observed, yet an attention to these circumstances alone are not sufficient to throw much light upon them, when unassisted with any knowledge of their real situation and dimensions.

XLIX. Aecount of New Publications.

A Treatise on the Culture and Management of Fruit-Trees, in which a new Method of Pruning and Training is fully described, $\varnothing^{\circ} \mathrm{c} . \Phi^{\circ} \mathrm{c} . \quad B y \mathrm{~W}$. FonsтTH, F.A.S. and F.S.A. Ëc. \$ீc. Third Edition. 8vo.

$\mathrm{T}_{\mathrm{r}}$ His work is so well known to the public already that any account of it from us would be superfluous. We only take notice of the present edition for the purpose of mentioning a new way of treating diseased trees, and to extract from it a testimonial highly creditable to Mr. Forsyth.

" 1 avail myself of this opportunity (says Mr. F.) to add a discovery which I have recently made, and which, as being calculated to save time and labour, may deserve attention.

“I Instead of paring away the bark, as had heretofore been the practice, and covering the stem with the composition, I now merely scrape off the loose bark, and apply a mixture of cow-dung and urine only (made to the consistence of a thick pairt) with a painter's brush, covering the stem carefully over. This softens the old scabrous bark, which peels off during the tollowing winter and spring, and is succeeded by a fine smooth new bark."

"To Mr. Forsyth, Royal Gardens, Kensington. "sir,

"As you had the goodness lately to give us an oppor* tunity of examining several trees in Kensington gardens in 